MATHEMATICA APPLICANDA

Vol. 46(1) 2018, p. 49-57

doi: $10.14708 /$ ma.v46il.6371

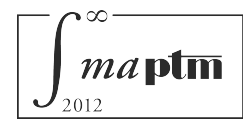

Antoni Leon Dawidowicz (Kraków)

Anna Poskrobko* (Białystok)

\title{
Mathematical model of bats' subpopulations development
}

\begin{abstract}
The paper deals with the description of the mathematical model of bats' subpopulations and fission-fusion societies development. The model is based on the system of ordinary differential equations. Bats' behaviour and their searching strategy is presented on the basis of cavity roosting bats living in Białowieża Forest located in Poland. Theoretical results are illustrated by a computer simulation and its comparison with biological remarks.
\end{abstract}

2010 Mathematics Subject Classification: 92B05, 92D25, 91D10.

Key words and phrases: bats, population, differential equations, numerical simulations.

1. Introduction We present the construction of the mathematical model describing the growth of bats' population. We consider a location of natural roosts in the area and some natural bats' abilities which determine searching and populating tree cavities. Location of roosts and their capacity determine the development of subpopulations and fission-fusion societies. We describe the bats' behaviour and their searching strategy on the basis of cavity roosting bats (Nyctalus noctula and Nyctalus leisleri) living in Białowieża Forest located in Poland. Due to the difficulty of observing bats in the field, the knowledge of their searching strategies is extremely poor and limited to experiments conducted with artificial roosts such as bat boxes, or conducted under laboratory conditions (see [3], [4], [5], [6]). Biological remarks concerning bats' behaviour, their natural skills and habits we adapted from [4] and references therein. Bats are the only mammals capable to fly actively, predominantly leading nocturnal lifestyle. These animals, regardless of their age, are looking for hiding places throughout their life. One colony of bats can use up to a dozen hiding places within a year, changing them from time to time, while transporting their juveniles. Some species of bats form breeding colonies that spread to new places every few days. It allows to avoid parasites

* The contribution of Anna Poskrobko was supported by the Bialystok University of Technology grant $\mathrm{S} / \mathrm{WI} / 1 / 2016$ and funded by the resources for research by Ministry of Science and Higher Education 
developing in hollows, as well as reduce the risk of predation. In winter bats form large colonies consisting of individuals of both sexes. Some species of bats also migrate at this time of year, breaking the state of hibernation. It happens during long-term thermal warming. Then, bats look for cooler hiding places, where a lower temperature allows to reduce all their vital functions and reduce fat tissue consumption. Therefore, constant migration is a hallmark of bats life. Bats use echolocation for orientation in space, as well as for detecting, identifying and localizing food or roosts. The detection range for an object does not exceed $90 \mathrm{~m}$. Bats inhabit holes created by woodpeckers, cavities left by broken-off branches or spaces beneath bark. They usually select areas with a high density of trees suitable for roosting. Suitable roosts have to fulfil many conditions, such as offering protection from unfavourable weather and predators, or providing a suitable microclimate for temperature regulation. Roosts are especially important during the reproductive period, because their quality may influence the development of juveniles or breeding success. Bat social groups are often fission-fusion societies, which spread over multiple tree cavities, with the number of bats in each tree ranging from a few to several hundred individuals. Through grouping, they benefit from better protection from predators, increased movement efficiency, improved food discovery. Roosts are also recognised as "information centres". Bats can transfer information about the presence of cavities to conspecifics either actively or passively, using acoustic calls or behaviours such as swarming. There are three alternative strategies for finding resources: selecting places or objects that offer the highest chance of success, memorising the resource distribution once discovered and obtaining information from conspecifics. Wherein the process of finding new tree cavities is as follows (see [4]): 1) the bat chooses the area to initiate the search for new cavities in the vicinity of known roosts; 2 ) it locates a potential roost tree; 3 ) the bat inspects the trunk surface to detect an entrance to the cavity; 4) it inspects and evaluates roost's quality, $5)$ the information about the presence of a suitable new cavity is transferred to conspecifics through social calls that can be eavesdropped; 6) based on this information, the colony or part of the colony makes a decision on whether to use the cavity or not; 8) once detected, the cavity enters the pool of suitable and known cavities which can be reused in the future. Bats are long lived animals, thus they can gain benefits from learning and memory retention throughout their life. The memory of bats is specifically protected during hibernation. Bats' longevity compensates their low fertility - the female usually gives birth to only one juvenile each year, while the twins or triplets are rare.

In the paper we propose the mathematical model describing the development of a bats' colony and its division into subpopulations. In the model we consider the above biological remarks: the searching roosts strategy, limited detection range and spreading over many cavities. Our model is based on the system of ordinary differential equations. According to our knowledge there 
are no other similar theoretical models describing the development of bats' fission-fusion societies. We know only three papers [2], [4] and [7] concerning simulations of bat's behaviour and its searching strategy. Paper [4] contains a computer simulation based on $\mathrm{C}++$ programming language describing the cavity searching strategy for individuals in areas with different topography. The mathematical model proposed in [2] and [7] is based on the system of difference equations. It describes the behaviour and orbits of bats moving to a new roost.

In the next sections we introduce variables, coefficients and assumptions of the model. We illustrate theoretical results by computer simulations.

2. Variables, assumptions and construction of model The model is based on the system of $n$ ordinary differential equations, where $n \in \mathbb{N}$ is the number of roosts in the considered area. $x_{i}(t)$ denotes bats' population size in $i$-th tree cavity, $i=1, \ldots, n$. In our model we used the following coefficients:

- $k_{0}$ the birth coefficient, common for the whole population of bats;

- $c_{i}$ the capacity of $i$-tree cavity, for $i=1, \ldots, n$. Capacity of a roost means not only its volume, but also other conditions such as offering protection from unfavourable weather and predators, its location, suitable microclimate for temperature regulation, etc. $c_{i}$ equals the maximum number of individuals which can live in $i$-th tree cavity;

- $\xi_{i j}$ the distance between $i$-th and $j$-th tree cavity. It is clear that $\xi_{i j}=$ $\xi_{j i}$

- $a$ the maximum range of the detection in the bats' roosts searching strategy.

There are the following functions considered in the model:

- $k_{i}:[0, \infty) \rightarrow\left[-k_{0}, k_{0}\right], i=1, \ldots, n$, the growth functions depend on a population size in $i$-th tree cavity, respectively; $k_{i}(\tau)$ equals $k_{0}$ for arguments $\tau<c_{i}-\eta$ and $-k_{0}$ for $\tau>c_{i}+\eta$. Here $\eta$ is sufficient small. The function $k_{i}$ denotes growth and decline of a population in $i$-th cavity. It consists of proliferation, mortality and migration to the other tree roosts. In the case of a small population proliferation and mortality are the only causes of its development. As a population increases, individuals begin to migrate from $i$-th roost to others tree cavities. The migration starts at the moment when the population size has not yet reached the level of maximum capacity $c_{i}$ of $i$-th tree roost, hence the coefficient $\eta$ appears. Therefore we assume that the function $k_{i}$ is continuous and decreasing in the interval $\left(c_{i}-\eta, c_{i}+\eta\right)$.

- $\varphi:(0, \infty) \rightarrow[0,1]$ the function of the distance between two any tree cavities. $\varphi$ is decreasing on the interval $(0, a)$ and equals 0 outside this interval. 
We assume that the bats' colony living in $i$-th tree cavity uses the resources and capacity of this roost in the initial period of the development. When the capacity of $i$-th tree cavity becomes insufficient the individuals start to migrate. Suitable roosts located in the distance less than $a$ are settled. In the model we consider bats' sensory limitation (the coefficient $a$ ) and the roost searching strategy (only tree cavities with a surplus of resources are settled). The colony divides into subpopulations. The reproductive abilities of the migrating groups depend on the resources of the settled roosts and decrease as the populations increase. We get the following system of the equations

$$
x_{i}^{\prime}(t)=k_{i}\left(x_{i}(t)\right) x_{i}(t)+\sum_{j=1, j \neq i}^{n} \varphi\left(\xi_{i j}\right)\left(k_{0}-k_{j}\left(x_{j}(t)\right) \cdot x_{j}(t)\right.
$$

for $i=1, \ldots, n$. It should be noted, however, that the population in $i$-th roost cavity cannot increase unlimitedly, which could be observed in the above equation. Therefore, its right-hand side should be multiplied by the expression $J\left(\frac{x_{i}(t)}{c_{i}}\right)$ where $J(\tau)$ equals 1 for arguments $\tau<1-\sigma$ and 0 for $\tau>1$. Here $\sigma$ is sufficiently small. Such a definition of function $J$ has the biological justification. It describes the "attractiveness" of a given $i$-th roost cavity, which decreases with the increase of the population of bats inhabiting it. Using the function $J$ corresponds to the point 7 ) of the bats' searching strategy of new cavities described in Introduction, i.e. a possible decision on the migration of some individuals of a colony and the continuation of further searches for the rest of a subpopulation remaining in the old habitat. We assume that $J$ is differentiable on its domain. The equation in this case is the following

$$
\begin{aligned}
x_{i}^{\prime}(t)=k_{i}\left(x_{i}(t)\right) x_{i}(t)+ & \\
& {\left[\sum_{j=1, j \neq i}^{n} \varphi\left(\xi_{i j}\right)\left(k_{0}-k_{j}\left(x_{j}(t)\right) \cdot x_{j}(t)\right] \cdot J\left(\frac{x_{i}(t)}{c_{i}}\right) .\right.}
\end{aligned}
$$

Let $\gamma_{i} \in\left(c_{i}-\eta, c_{i}+\eta\right)$ be the only zero point of the function $k_{i}$ for any $i$. Here we will consider two cases when $\gamma_{i} \geq c_{i}$ and $\gamma_{i}<c_{i}$. For these two cases we will analyze a behaviour of the solutions. If $\gamma_{i} \geq c_{i}$ then equation (2) is in the following form

$$
x_{i}^{\prime}(t)=k_{i}\left(x_{i}(t)\right) x_{i}(t)
$$

for $x_{i} \geq c_{i}$ (because of $J\left(\frac{x_{i}(t)}{c_{i}}\right)=0$ ). The solution of this equation asymptotically converges to $\gamma_{i}$. For $x_{i} \leq c_{i}$ we have $J\left(\frac{x_{i}(t)}{c_{i}}\right)=1$ therefore the inequality

$$
x_{i}^{\prime}(t) \geq k_{i}\left(x_{i}(t)\right) x_{i}(t)
$$

is fulfilled. Hence, the solution is the increasing function for $x_{i} \leq \gamma_{i}$. After finite time it reaches the value $c_{i}$. Above this value equation (3) applies and 
we get the convergence to $\gamma_{i}$. Therefore, for the case $\gamma_{i} \geq c_{i}$ we get the convergence of the solutions to the value $\gamma_{i}$.

If $\gamma_{i}<c_{i}$ than for $x_{i} \geq c_{i}$ and $x_{i} \leq \gamma_{i}$ we get the convergence of the solutions to $\gamma_{i}$ according to the remarks from the first case. For $\gamma_{i}<x_{i}<c_{i}$ the values of the limits

$$
\lim _{t \rightarrow \infty} x_{i}(t) \in\left(\gamma_{i}, c_{i}\right)
$$

we can get solving the system

$$
k_{i}\left(x_{i}\right) x_{i}+\left[\sum_{j=1, j \neq i}^{n} \varphi\left(\xi_{i j}\right)\left(k_{0}-k_{j}\left(x_{j}\right)\right) \cdot x_{j}\right] \cdot J\left(\frac{x_{i}}{c_{i}}\right)=0,
$$

for $i=1, \ldots, n$.

3. Computer simulations Computer simulations are based on programm MAPLE 16. The choices of the functions used in the simulations are as follows

$$
k_{i}(x)=\left\{\begin{array}{ccc}
k_{0} & \text { for } & x \leq c_{i}-\tau \\
\frac{k_{0}}{\tau}\left(c_{i}-x\right) & \text { for } & c_{i}-\tau \leq x<c_{i}+\tau \\
-k_{0} & \text { for } & x \geq c_{i}+\tau
\end{array}\right.
$$

where $i=1, \ldots, n$,

$$
\begin{gathered}
\varphi(x)=\left\{\begin{array}{cc}
1-\frac{x}{a} & \text { for } x<a \\
0 & \text { for } x \geq a
\end{array}\right. \\
J(x)=\left\{\begin{array}{ccc}
1 & \text { for } \quad x<\frac{7}{8} \\
\frac{1}{2}+\frac{1}{2} \sin \left(-8 \pi x+\frac{15}{2} \pi\right) & \text { for } \frac{7}{8} \leq x<1 . \\
0 & \text { for } \quad x \geq 1
\end{array}\right.
\end{gathered}
$$

3.1. Case A We consider three roosts with the capacities $c_{1}=50$, $c_{2}=20$ and $c_{3}=10$. The distances between these tree cavities are the following $\xi_{12}=5, \xi_{13}=5, \xi_{23}=9$. The chosen maximum range of the detection is $a=90$. We fix $k_{0}=0.2$ and $\tau=2$. In Figures $1-3$ we present the graphs of the functions of the model. We choose the initial conditions in the model: $x_{1}(0)=0, x_{2}(0)=0, x_{3}(0)=5$. Therefore, the only one of three tree cavities is inhabited. In Figure 4 we present numerical simulations.

We can see that bats' colony living in the third tree cavity uses the resources of this roost in the initial period of the development. When the sources run out, then individuals start to migrate to the other tree cavities. Finally, the sizes of three bats' subpopulations stabilize on the levels of the capacities of each tree roosts.

3.2. Case $\mathbf{B}$ Three roosts with the capacities $c_{1}=50, c_{2}=20$ and $c_{3}=10$. The chosen maximum range of the detection is $a=90$. The distances 

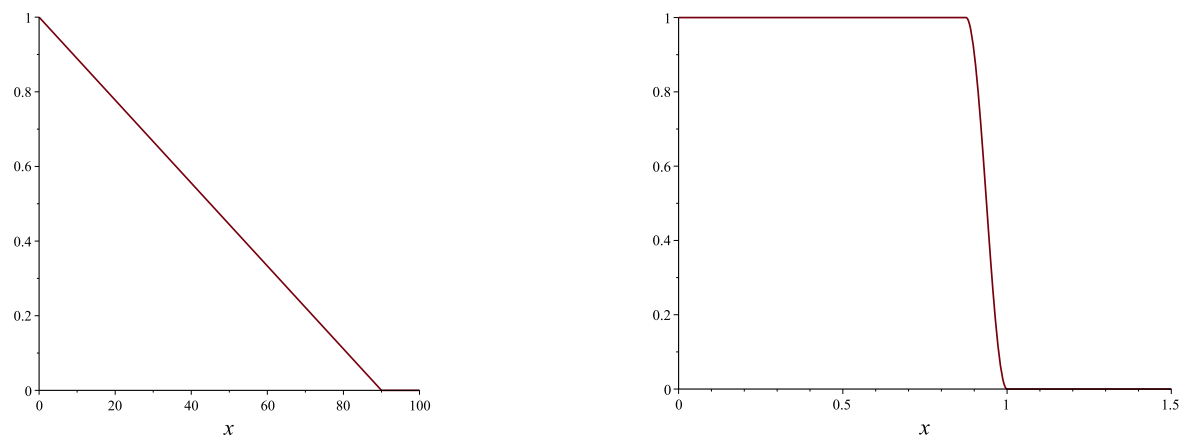

Figure 1: The graph of the function $\varphi$. Figure 2: The graph of the function $J$.
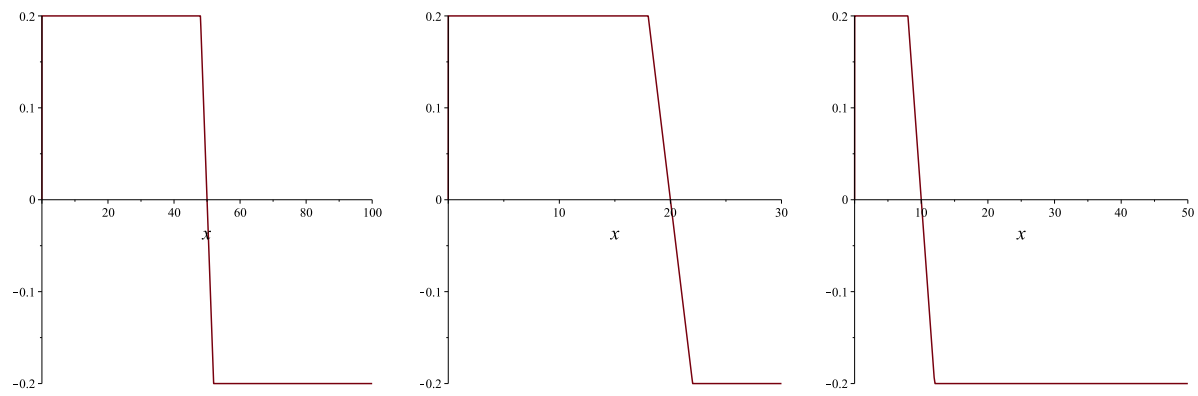

Figure 3: The graphs of the functions $k_{1}, k_{2}$ and $k_{3}$.

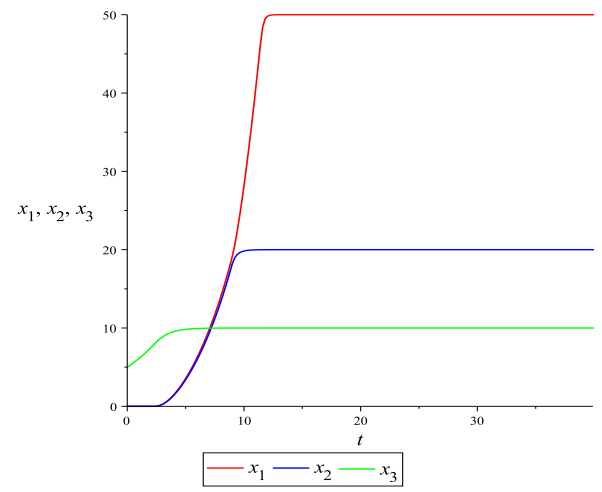

Figure 4: Case A. Initial conditions: $x_{1}(0)=0, x_{2}(0)=0, x_{3}(0)=5$.

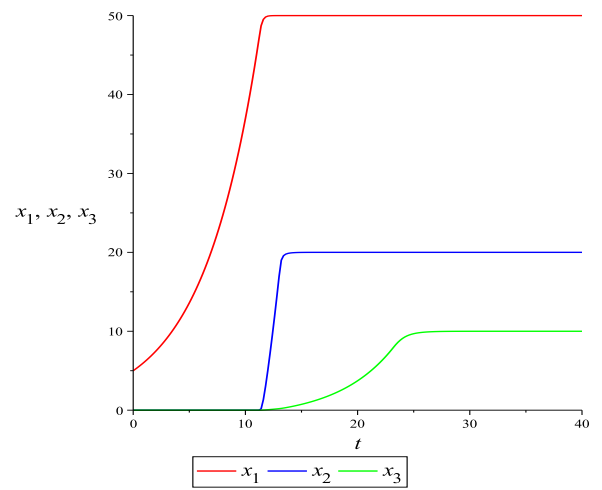

Figure 5: Case B. Initial conditions: $x_{1}(0)=5, x_{2}(0)=0, x_{3}(0)=0$.

between these tree cavities are the following $\xi_{12}=2, \xi_{13}=89, \xi_{23}=88$. Therefore, the third roost is for the bats at the limit of their detection range. We fix $k_{0}=0.2$ and $\tau=2$. The initial conditions in the model: $x_{1}(0)=5$, $x_{2}(0)=0, x_{3}(0)=0$. Theoretical results are in Figure 5 .

3.3. Case $\mathbf{C}$ We add the fourth tree cavity with $c_{4}=20$ to the case 
B. The distances between tree cavities from the case B and the additional fourth roost are the following: $\xi_{14}=113, \xi_{24}=107, \xi_{34}=28$. Therefore, the fourth roost is out bats' detection range from first and second cavities. We can observe the migration to the fourth tree cavity only from the third roost - see Figure 6 (initial conditions $x_{1}(0)=5, x_{2}(0)=0, x_{3}(0)=0, x_{4}(0)=0$ ).

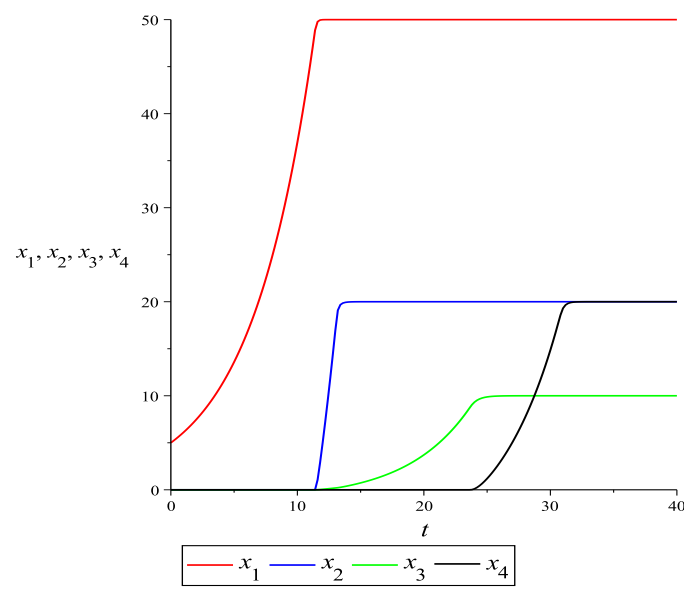

Figure 6: Case C. Initial conditions: $x_{1}(0)=5, x_{2}(0)=0$, $x_{3}(0)=0, x_{4}(0)=0$.

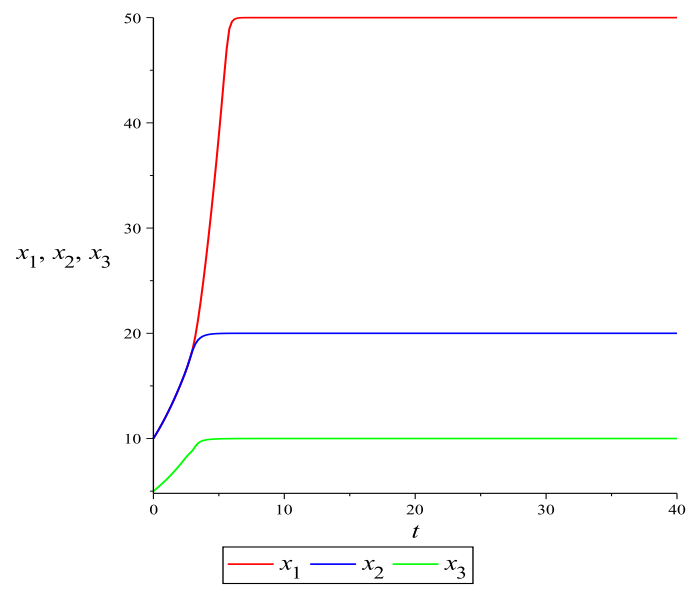

Figure 7: Case D. Initial conditions: $x_{1}(0)=10, x_{2}(0)=10$, $x_{3}(0)=5$.

3.4. Case D We consider case A with new initial conditions $x_{1}(0)=10$, $x_{2}(0)=10, x_{3}(0)=5$, see Figure 7 . All tree cavities are inhabited. We can see that each population growth is independent, with unnoticeable migration.

4. Conclusions and remarks The theoretical model quite well reflects the described natural bats' abilities: constant migration, limited detection range, settling tree cavities with a surplus of resources, dividing into subpopulations. We can expand the model considering bats' abilities to learning and eavesdropping social calls (see [1]). Memory can also play an important role in decision making processes: where and when to search for new cavities. The model with delays could reflect the ability to build "cognitive maps" for orientation in space (see [8]) and the possibility to return to the found roost even after the hibernation period. Under the current assumptions, we do not observe oscillations. The subpopulation sizes always converge to the values close to the capacities of the roosts. We suspect that oscillations of solutions would be possible under the assumption of variable habitat capacity. It has biological justification. Bats change habitats due to lack of space in the roost, lack of food in the nearby hunting area, to avoid parasites developing in tree cavities and reduce the risk of predation. At the same time, bats have memory skills about the distribution of habitats in the area and often return to 
roosts previously inhabited, and in which conditions may have improved. Introducing the variable capacity of the habitat is an idea for further work on the generalization of the model.

\section{References}

[1] J. Furmankiewicz, I. Ruczyński, R. Urban, and G. Jones. Social calls provide tree-dwelling bats with information about the location of conspecifics at roosts. Ethology, 117:480-489, 2011. doi: 10.1111/j.14390310.2011.01897.x. Cited on p. 55.

[2] E. Girejko, R. Jankowski, and E. Schmeidel. Model matematyczny opisujaccy zachowanie nietoperzy zamieszkujących dziuple. Portal CZM, 2015. Cited on p. 51.

[3] G. Kerth. Group decision-making in fission-fusion societie. Behavioural Processes, 84:662-663, 2006. doi: 10.1016/j.beproc.2010.02.023. Cited on p. 49.

[4] I. Ruczyński and K. A. Bartoń. Modelling sensory limitation: The role of tree selection, memory and information transfer in bats' roost searching strategies. PLOS ONE, 7:e44897, 2012. doi: 10.1371/journal.pone.0044897. Cited on pp. 49, 50, and 51.

[5] I. Ruczyński, E. K. V. Kalko, and B. M. Siemers. The sensory basis of roost finding in a forest bat, nyctalus noctula. Journal of Experimental Biology, 210:3607-3615, 2007. doi: 10.1242/jeb.009837. Cited on p. 49.

[6] I. Ruczyński, E. K. V. Kalko, and B. M. Siemers. Calls in the forest: how bats find tree cavities. Ethology, 115:167-177, 2009. doi: 10.1111/j.14390310.2008.01599.x. Cited on p. 49.

[7] E. Schmeidel and E. Girejko. On mathematical model of bats' roost searching strategies. Wulfenia Journal, 23:67-75, 2016. Cited on p. 51.

[8] A. Tsoar, R. Nathan, Y. Bartan, A. Vyssotski, G. Dell'Omo, and N. Ulanovsky. Large-scale navigational map in a mammal. Proceedings of the National Academy of Sciences, 108(37):E718-E724, 2011. ISSN 0027-8424. doi: 10.1073/pnas.1107365108. Cited on p. 55.

\section{Matematyczny model rozwoju subpopulacji nietoperzy.}

Antoni Leon Dawidowicz i Anna Poskrobko

\footnotetext{
Streszczenie

Artykuł dotyczy opisu matematycznego modelu subpopulacji nietoperzy oraz rozwoju procesu zasiedlania nowych dziupli. Model oparty jest na systemie równań różniczkowych zwyczajnych. Zachowania nietoperzy i ich strategię poszukiwań przedstawiono na podstawie obserwacji nietoperzy zamieszkujących dziuple w Puszczy Białowieskiej. Wyniki teoretyczne ilustruje symulacja komputerowa i jej porównanie
} 
z uwagami biologicznymi.

Klasyfikacja tematyczna AMS (2010): 92B05, 92D25, 91D10.

Słowa kluczowe: nietoperze, populacja, równania różniczkowe, symulacja numeryczna.

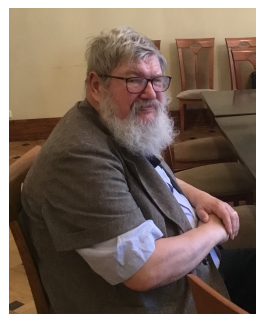

Antoni Leon Dawidowicz, a mathematician, Associate Professor of Jagiellonian University. Born in 11 September 1952 in Kraków. In 1976 he graduated from the mathematical studies at Jagiellonian University. Since the graduation he has been working in the Institute of Mathematics of this University incessantly. In the years 1990-1994 he was the Councilor of city of Kraków, 2001-2007 the president of the Polish Tatra Mountains Society. Member of the Polish National Group of the International Society of Clinical Biostatistics. 2011-2016 the president of Kraków branch of the Polish Mathematical Society. His research papers are listed in the European Mathematical Society, FIZ Karlsruhe, and the Heidelberg Academy of Sciences bibliography database known as zbMath ${ }^{a}$ under ai:dawidowicz.antoni-leon, in MathSciNet under ID: 197295.

${ }^{a}$ The database maintained by European Mathematical Society, FIZ Karlsruhe, and the Heidelberg Academy of Sciences. Former Zentralblatt für Mathematik

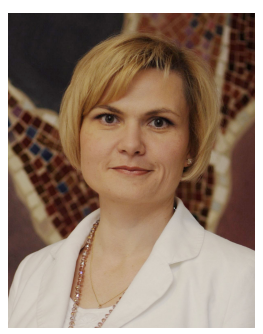

Anna Poskrobko, a mathematician affiliated to the Faculty of Computer Science at Bialystok University of Technology. She got $\mathrm{PhD}$ degree in the mathematical science in 2007 at Jagiellonian University in Cracow. She was the head of the Center for Popularization of Mathematics „Signum” in 2008-2014. Poskrobko's main research areas are biomathematics and differential equations. Her research papers are listed in the European Mathematical Society, FIZ Karlsruhe, and the Heidelberg Academy of Sciences bibliography database known as zbMath under ai:Poskrobko.Anna, in MathSciNet under ID: 784648 and ORCID ID:0000-0003-3525-1996.

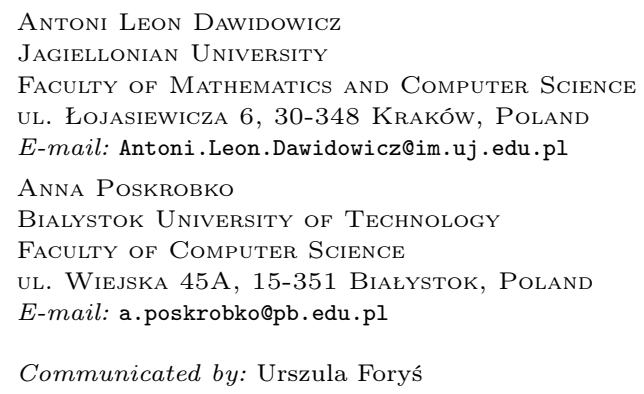

